\title{
Differences between all-around results in women's artistic gymnastics and ways of minimizing them
}

Authors' Contribution: A Study Design B Data Collection

C Statistical Analysis D Data Interpretation E Manuscript Preparation F Literature Search G Funds Collection

\author{
Almir Atiković1 ABCDEFG, Edina Kamenjašević1 ABCDEFG, Amra Nožinović Mujanović ${ }^{1}$ DEF, \\ Edin Užičanin ${ }^{1 \mathrm{BC}}$, Muhamed Tabaković2 CDF, Mijo Ćurićc ${ }^{\text {BC }}$ \\ ${ }^{1}$ Faculty of Physical Education and Sport, University of Tuzla, \\ Tuzla, Bosnia and Herzegovina \\ ${ }^{2}$ Faculty of Sport and Physical Education, University of Sarajevo, \\ Sarajevo, Bosnia and Herzegovina \\ ${ }^{3}$ Faculty of Education - Kinesiology, Josip Juraj Strossmayer University of Osijek, \\ Osijek, Croatia
}

\section{abstract}

Background: In the present study, the main goal was to establish whether the disciplines are equal and should the Code of Points (COP) women's artistic gymnastics be revised in terms of point standardization on apparatus.

Material and methods:

Results: The biggest differences are even two points between the two apparatus vault and balance beam. Vault compared to other apparatus is different for 1.559 points. Presentation of correlations between each apparatus the evidence that nothing has changed significantly in recent years, whereas correlations of the difficulty values of elements are extremely high between the present COP.

Conclusions: With this analysis, we have found that the results achieved at the vault and other apparatus were significantly different in terms of success in all-around competition.

Key words: women's artistic gymnastics, judging, Code of Points (FIG), correlation analysis, competitive performance, modeling.

\section{article details}

Article statistics: Word count: 4,479; Tables: 4; Figures: 2; References: 43

Received: December 2019; Accepted: March 2020; Published: September 2020

Full-text PDF: http://www.balticsportscience.com

Copyright @ Gdansk University of Physical Education and Sport, Poland

Indexation: Celdes, Clarivate Analytics Emerging Sources Citation Index (ESCI), CNKI Scholar (China National Knowledge Infrastructure), CNPIEC, De Gruyter - IBR (International Bibliography of Reviews of Scholarly Literature in the Humanities and Social Sciences), De Gruyter - IBZ (International Bibliography of Periodical Literature in the Humanities and Social Sciences), DOAJ, EBSCO - Central \& Eastern European Academic Source, EBSCO - SPORTDiscus, EBSCO Discovery Service, Google Scholar, Index Copernicus, J-Gate, Naviga (Softweco, Primo Central (ExLibris), ProQuest - Family Health, ProQuest - Health \& Medical Complete, ProQuest - Illustrata: Health Sciences, ProQuest - Nursing \& Allied Health Source, Summon (Serials Solutions/ProQuest, TDOne (TDNet), Ulrich's Periodicals Directory/ulrichsweb, WorldCat (OCLC)

Funding: This research received no specific grant from any funding agency in the public, commercial, or not-for-profit sectors. Authors have declared that no competing interest exists.

Associate Professor Almir Atiković, Ph.D.; University of Tuzla, Faculty of Physical Education and Sport, 2. Oktobra 1, 75000 Tuzla, Bosnia and Herzegovina; phone: +387 35278 536; e-mail: almir.atikovic@untz.ba.

Open Access License:

This is an open access article distributed under the terms of the Creative Commons Attribution-Non-Commercial-NoDerivatives 4.0 International (https://creativecommons.org/licenses/by-nc-nd/4.0/), which permits use, distribution and reproduction in any medium, provided the original work is properly cited, the use is non-commercial and is otherwise in compliance with the license. 


\section{INTRODUCTION}

In the program of the first Olympic Games (OG), artistic gymnastics was presented for the first time in 1896 in Greece (Athens), and in 1903 at the World Championship (WCh) in Belgium (Antwerp), while at the European Championship (ECh) it was presented for the first time in 1955, in Germany (Frankfurt). Women's artistic gymnastics (WAG) first appeared at the OG in 1928 in the Netherlands (Amsterdam), at the WCh it appeared in 1934 in Hungary (Budapest), and at the ECh in 1957 in Greece (Athens) [1]. Before 1996, competitions in gymnastics were different from now. On the first day of competition, in qualifications, gymnasts performed compulsory exercises, stipulated by the Fédération Internationale de Gymnastique (FIG). While on the second day, they performed free exercises. For the final result, points for both performances of gymnasts were taken into consideration.

Reasons given for eliminating the compulsory exercises include not being interesting for television or the general public viewing, the scoring, especially with 'new life', simplified following the competition results, making it more attractive to the public. Also, the competition was shortened which was less taxing for the gymnasts [1].

As the sport of gymnastics developed more, the Code of Points (COP) in this sport improved. At that time, the evaluation of the presented composition was made on the basis of insufficiently defined instructions from technical regulations (FIG), possible arrangement and alignment of the judges' criteria before the competition and, to the fullest extent, on the basis of judges' personal attitude and experience [2]. First official (COP) FIG was issued in 1948, printed on twelve pages. Before 1948, only general data from the technical ordinance was used. In 1964, a lot of experience gained in previous years led to the creation of new COP, which contained elements (A, B and C), combinations and other general provisions.

Today, for the assessment of artistic gymnastics, the international competitive COP for assessment of men's and women's artistic gymnastics is in effect, which are improved and published after the OG finish. The female competition COP for the evaluation of the technical commission is composed by Women's Technical Committee, FIG. After the OG in 2004, the FIG made big changes to the COP. One of these changes was the implementation of a new philosophy of an open scoring system, prepared by Fink and Fetzer [3], which had previously been introduced at the FIG symposium in Lugano in 1993.

The biggest changes happened in 2006, when the assessment of composition ceased to be limited to ten points, as the highest possible point. Since 2006, the point is divided into $\mathrm{D}$ and $\mathrm{E}$ parts. Independent members of the $\mathrm{D} \& \mathrm{E}$ jury are on all apparatus: $\mathrm{D}$ jury evaluates difficulty value, special require $\neg$ ments and bonus points starting from 0.00 points to more, and E jury evaluates the performance of an exercise (technique of execution, body posture, and balance) and provides deductions for the performance from ten points to lower. D jury determines the initial value of an exercise, and the E jury registers performance errors due to technical performance, body posture and balance of exercise performance so that those two grades would at the end sum up to the final score.

The basis of all competitions in women's artistic gymnastics is the all-around event. Artistic gymnastics is a typical multidisciplinary sport with four disciplines 
The basis of all competitions in women's artistic gymnastics is the all-around event. Artistic gymnastics is a typical multidisciplinary sport with four disciplines in the women's category: Vault (VT), Uneven Bars (UB), Balance Beam (BB) and Floor Exercise (FX). Women perform at the competition the maximum 8 highest difficulty value (DV) including the dismount are counted | on UB, BB and FX. Currently, in the OG or WCh competition, the meeting is divided into several sessions that are held on different days: qualification (CI), all-around finals (C-II), team finals (C-III) and event finals (C-IV). COP for the evaluation of artistic gymnastics includes nine levels of difficulty. The I initial degree of difficulty is at level $\mathrm{A}=0.10$ points, and the next levels are | $\mathrm{B}=0.20$ pts., $\mathrm{C}=0.30$ pts., $\mathrm{D}=0.40$ pts., $\mathrm{E}=0.50$ pts., $\mathrm{F}=0.60$ pts., $\mathrm{G}=0.70$ pts., $\mathrm{H}=0.80$ pts. and $\mathrm{I}=0.90$ pts. [4]. The final one represents the greatest degree of severity. The primary purpose of the WAG COP (FIG, 2017) is to "provide an objective means of evaluating gymnastics exercises at all levels of FIG official competitions, a ssure the identification of the best gymnast in any | competition" [4].

In artistic gymnastics, the emphasis is on the aesthetic component, which must be performed in accordance with the conventionally defined movement structure. Although the methods of evaluation in individual sports differ from one another (either by the number of judges, the criteria set or how the final result is calculated), for individual sports such as figure skating, diving, synchronized swimming, gymnastics (acrobatics, aerobics, rhythmics, trampoline, artistics), dressage (gp \& gp special and gp freestyle), ski jumping, freestyle snowboard (snowboard-halfpipe and slopestyle), dance, aerials, etc., it is characteristic that judges evaluate the quality of competitive effects on the basis of the displayed compositions or jumps [5].

The specificity of the gymnastics competition is that the result is not expressed by physical units (meter, kilogram or second), but the technique of performing exercises is evaluated strictly and subjectively on the basis of the determined difficulty value of the individual elements and composition of the exercise | as a whole on the basis of the gymnastics COP. Artistic gymnastics is a sport with a primary requirement of adopting the technique of the most varied specific exercises. This means that learning new, more complex and demanding elements is an everyday principle of the training process [6]. Several aspects of judging performance were already described in the past at various competitions and several proposals for further improvements in this field were made [7-20].

The main objective of the study was to determine whether the disciplines in women's all-around event are equal in the function of the maximum manifestation of the all-around event potential [4].

\section{MATERIAL AND METHODS}

\section{PARTICIPANTS}

The number of competitors in the qualification round (C-I) differed in various years. The sample included all-around senior female gymnasts who participated in the qualification (C-I) competitions at WCh held in: 2009 London (GBR), $\mathrm{n}=79 ; 2010$ Rotterdam (NED), $\mathrm{n}=140 ; 2011$ Tokyo (JPN), $\mathrm{n}=154 ; 2013$ Antwerp (BEL), $\mathrm{n}=80 ; 2014$ Nanning (CHN), $\mathrm{n}=154 ; 2015$ Glasgow (GBR), $\mathrm{n}=190 ; 2017$ Montreal (CAN), n=74; 2018 Doha (QAT), n=143 and 2019 Stuttgart (GER), $\mathrm{n}=173$. 


\section{VARIABLES}

We have made analysis of the chronological age trend from the official book results of the Fédération Internationale de Gymnastique (FIG) of all-around female participants in WAG for the period of 2009 to 2019. All data for this study was obtained from the website: [https://www.longinestiming.com/ gymnastics]. We made variables of judges' E score, D score and FS final score (D + E score) from 4 apparatus: Vault (VT), Uneven Bars (UB), Balance Beam (BB) and Floor Exercise (FX).

\section{DATA PROCESSING METHODS}

For the statistical analysis, we used the Statistical Package for the Social Sciences - Version 17.0 (SPSS 23.0, Chicago, USA) and Microsoft Office Excel 2013. Descriptive statistics were calculated using the mean values (M) as a measure of central tendency, standard deviation (SD) as a measure of dispersion, and minimum (Min) and maximum (Max) as measures of data range. Five percent level of significance $(p<0.05)$ was considered for all statistic parameters except Pearson correlation, which was $(p<0.01)$. Pearson correlation was performed to analyze the association between the degree of the difficulty of elements in the gymnasts' routines comparing the same elements in two different cycles of judging (FIG, 2017-2013, 2017-2009, 2013-2009). With this Pearson correlation, we will see if there was a change in the difficulty value of the all elements. By Pearson correlation, we try to compare the allaround final score of gymnasts, and by the chronological age, we will try to determine whether, with increasing age, the result can follow the progress of the gymnasts' development. We used Paired Sample T-Test, to determine whether there were significant differences between the apparatus, and how much the difference is expressed in points. This analysis focused on the final WAG all-around results value of the each apparatus performed by gymnasts in a total of 1,187 competition routines in the World Championships from 2009 to 2019. To calculate the chronological age, the following formulas from the Microsoft Office Excel 2013 package were used.

For the total number of days of one's age since the date of birth until the first day of the competition qualifications:

Calculation formula $=$ DATEDIF $(A 1 ; B 1 ; " d ")$

For the total number of years of one's age since the date of birth until the first day of the competition qualifications:

Calculation formula $=$ DATEDIF $($ days $\mathrm{x} 0.0027397260273973$ years $)$

\section{RESULTS}

In the correlations matrix (Table 1), variables from the WAG COP (FIG, 2009; $2013,2017)$ effected a statistically significant correlation with all variables. The vault apparatus (VT) had the highest values of multiple correlation: VT2017VT2013 ( $\left.r^{2}: 0.968, p<0.01\right)$, VT2013-VT2009 $\left(r^{2}: 0.996, p<0.01\right)$ and VT2019VT2019 $\left(r^{2}: 0.953, p<0.01\right)$. The lowest values of multiple correlations $\left(r^{2}\right)$ concerned the balance beam (BB) apparatus: BB2019-BB2013 $\left(r^{2}: 0.899, p<\right.$ $0.01)$, BB2013-BB2009 $\left(r^{2}: 0.925, p<0.01\right)$ and BB2019-BB2009 $\left(r^{2}: 0.876\right.$, $p<0.01$ ). 
Table 1. Comparison between 3 Olympic cycles and Pearson's correlation coefficient between all $\square$ elements in Code of Points (FIG) from 2009 to 2017 for Women's Artistic Gymnastics.

\begin{tabular}{lcccc} 
Apparatus & Correlations & $2017-2013$ & $2013-2009$ & 2017-2009 \\
\hline \multirow{2}{*}{ Vault (VT) } & $r$ & 0.984 & 0.996 & 0.976 \\
& $r^{2}$ & 0.968 & 0.996 & 0.953 \\
\hline \multirow{2}{*}{ Uneven Bars (UB) } & $r$ & 0.986 & 0.984 & 0.973 \\
& $r^{2}$ & 0.973 & 0.968 & 0.946 \\
\hline \multirow{2}{*}{ Balance Beam (BB) } & $r$ & 0.948 & 0.962 & 0.936 \\
& $r^{2}$ & 0.899 & 0.925 & 0.876 \\
\hline \multirow{2}{*}{ Floor Exercise (FX) } & $r$ & 0.980 & 0.969 & 0.949 \\
& $r^{2}$ & 0.962 & 0.939 & 0.901 \\
\hline
\end{tabular}

Note: Correlation is significant at the 0.01 level (2-tailed).

In view of all the results (Table 2), the results of VT in all competitions have significantly higher value of the final score compared to other apparatus in all competitions. Value rating ranges from VT2018 - 13.080 points to VT2014 13.755 points. The lowest values left the female competitors at UB 2009-2011, 2014-2015 and 2019, BB 2013, 2017-2019.

Table 2. Mean values of final score on each apparatus

\begin{tabular}{cccccc}
\multicolumn{2}{c}{ Apparatus } & Vault & Uneven Bars & Balance Beam & Floor Exercise \\
\hline Year & N & Final score & Final score & Final score & Final score \\
\hline 2009 & 79 & 13.286 & 11.949 & 12.279 & 12.343 \\
2010 & 140 & 13.505 & 11.930 & 12.441 & 12.808 \\
2011 & 154 & 13.434 & 11.868 & 12.527 & 12.495 \\
2013 & 80 & 13.706 & 12.320 & 12.224 & 12.413 \\
2014 & 154 & 13.755 & 11.995 & 12.365 & 12.430 \\
2015 & 190 & 13.724 & 11.641 & 12.014 & 12.595 \\
2017 & 74 & 13.246 & 12.088 & 11.084 & 11.987 \\
2018 & 143 & 13.080 & 11.602 & 11.392 & 12.050 \\
2019 & 173 & 13.387 & 11.799 & 11.218 & 12.019 \\
\hline
\end{tabular}

Analyzing the results in arithmetical environments of all variables, the highest values were recorded at WCh 2019 - 20.18 years of age, and the lowest at WCh 2009 - 18.30 years of age. According to the results presented in (Table 3), female participants got older from WCh 2009 to WCh 2019 by 1.88 years (Fig. 1). A significant difference in age between 2009 and 2019 was found (t243.845 $=4.766, p<.001)$. There is a statistically significant correlation between the years of chronological age and the result of all-around competitions in the following years WCh 2014 ( $r$ : 0.041, $p<0.05$ ), WCh 2015 ( $r: 0.033, p<0.05$ ). Figure 2 shows the box-plots for women's all-around qualifications final score from 2009 to 2019. It is evident that the trend of increasing the score happens gradually after the end of the Olympic Games.

The series of $t$-tests (Table 4) shows that the finals scores on the VT are significantly higher than on all other apparatus. All pairs and differences between vault and other disciplines are significant. The difference between the VT final score - BB final score is: 2019 - 2.168 points, 2018 - 1.687 pts., $2017-2.161$ pts. In the past cycles, COP from 2009 to 2012 and COP from 2013 to 2016, the biggest differences were found between VT final score and UB final score. 
Table 3. Pearson correlation coefficient between average age and women's all-around qualification final score

\begin{tabular}{ccccccccc} 
Year & $\mathrm{N}$ & $\begin{array}{c}\text { Average } \\
\text { age }\end{array}$ & Min & Max & M & SD & $\begin{array}{c}\text { Correlation } \\
\text { coefficient }\end{array}$ & Sig. \\
\hline 2009 & 79 & 18.30 & 36.350 & 57.400 & 49.858 & 4.708 & -.136 & .231 \\
2010 & 140 & 18.33 & 42.165 & 60.666 & 50.686 & 4.025 & .152 & .073 \\
2011 & 154 & 18.98 & 40.341 & 60.157 & 50.324 & 4.318 & .006 & .939 \\
2013 & 80 & 19.04 & 42.099 & 60.133 & 50.664 & 4.266 & -.042 & .710 \\
2014 & 154 & 19.43 & 40.365 & 59.599 & 50.546 & 3.842 & .165 & $.041^{*}$ \\
2015 & 190 & 19.67 & 33.899 & 61.598 & 49.976 & 4.683 & .155 & $.033^{*}$ \\
2017 & 74 & 19.40 & 33.431 & 55.933 & 48.406 & 4.398 & .005 & .964 \\
2018 & 143 & 19.78 & 38.565 & 60.965 & 48.125 & 3.956 & .088 & .293 \\
2019 & 173 & 20.18 & 36.599 & 59.432 & 48.470 & 4.111 & .070 & .359 \\
\hline
\end{tabular}

Note: *Correlation is significant at the 0.05 level (2-tailed).

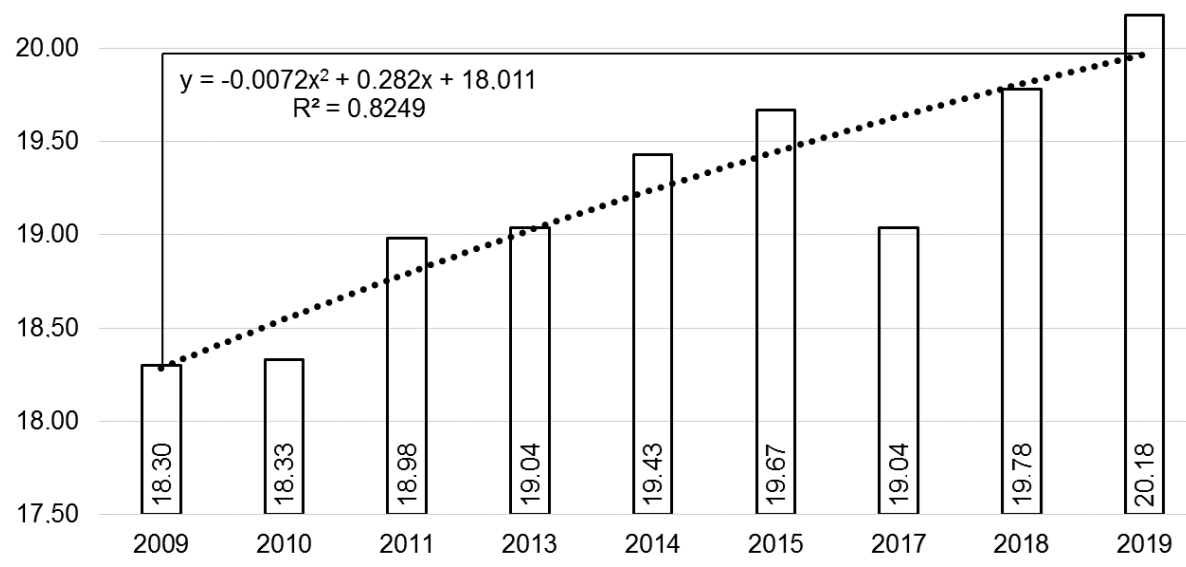

Fig. 1. Average age in women's all-around qualifications, second-order polynomial-regression equations, 2009-2019

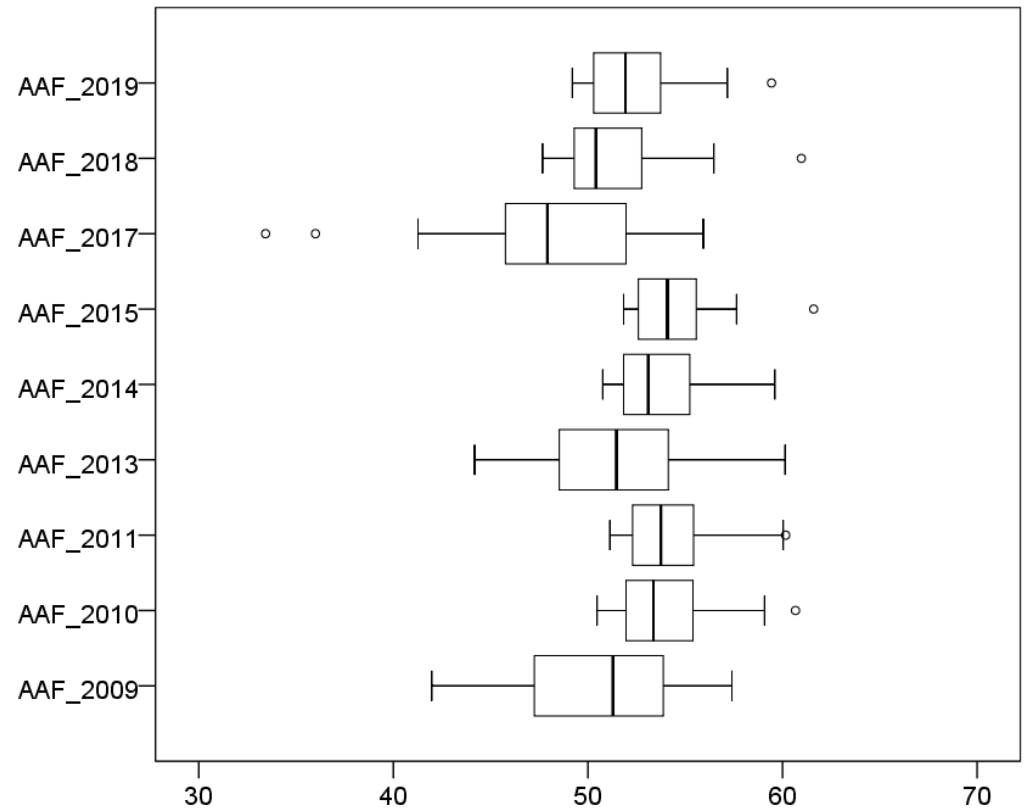

Fig. 2. Boxplot of women's all-around qualifications final score. Data are presented as mean $\pm 95 \%$ confidence interval 
Baltic Journal of Health and Physical Activity 2020; 12 (3): 80-91

Journal of Gdansk University of Physical Education and Sport

e-ISSN 2080-9999

Table 4. The differences between final scores on different apparatus

\begin{tabular}{|c|c|c|c|c|c|c|c|c|c|c|}
\hline \multicolumn{2}{|c|}{$\begin{array}{c}\text { Pair combinations } \\
\text { apparatus }\end{array}$} & 2009 & 2010 & 2011 & 2013 & 2014 & 2015 & 2017 & 2018 & 2019 \\
\hline Pair 1 & $\begin{array}{l}\text { VTfinal score - } \\
\text { UBfinal score }\end{array}$ & $1.337^{*}$ & $1.575^{*}$ & $1.565 *$ & 1.386 & $1.759 *$ & $2.082 *$ & 1.157 & 1.478 & 1.587 \\
\hline Pair 2 & $\begin{array}{l}\text { VTfinal score - } \\
\text { BBfinal score }\end{array}$ & 1.006 & 1.063 & .906 & $1.481 *$ & 1.389 & 1.710 & $2.161^{*}$ & 1.687* & $2.168^{*}$ \\
\hline Pair 3 & $\begin{array}{l}\text { VTfinal score - } \\
\text { FXfinal score }\end{array}$ & .942 & .696 & .938 & 1.292 & 1.324 & 1.128 & 1.258 & 1.029 & 1.368 \\
\hline Pair 4 & $\begin{array}{l}\text { UBfinal score - } \\
\text { BBfinal score }\end{array}$ & .330 & .511 & .658 & $.095 * *$ & .370 & .372 & 1.004 & $.209 * *$ & .581 \\
\hline Pair 5 & $\begin{array}{l}\text { UBfinal score - } \\
\text { FXfinal score }\end{array}$ & .394 & .878 & .627 & $.093 * *$ & .434 & .954 & $.101^{* *}$ & .448 & .219 \\
\hline Pair 6 & $\begin{array}{l}\text { BBfinal score - } \\
\text { FXfinal score }\end{array}$ & $.063^{* *}$ & .366 & .031 & $.189 * *$ & $.064 * *$ & .581 & .903 & .657 & .800 \\
\hline
\end{tabular}

Note: Vault (VT), Uneven Bars (UB), Balance Beam (BB), Floor Exercise (FX).

* Highest difference (points) with statistical significance at the level 0.05 level (2-tailed).

** There is no statistical significance at the level 0.05 level (2-tailed).

\section{DISCUSSION}

Authors [7] show relatively similar results of correlations between COP in MAG. There is an enormous distinction between a COP from 1964 to 2009 year wherever the correlations were less than 47 percent. However, considering the fact that there is a high correlation between the scores of different vault COP's from 1964 to 2009 (correlations between COPs (FIG) are: 1) 19711964: $r^{2}=0.95$; 2) 1978-1971: $r^{2}=0.89$; 3) 1985-1978: $r^{2}=0.76$; 4) 1989-1985: $r^{2}=0.76$; 5) 1997-1993: $r^{2}=0.79$; 6) 2001-1997: $r^{2}=0.87$; 7) 2006-2001: $r^{2}=0.98$; 8) 2009-2006: $r^{2}=1$. The overview of changes and correlations between the difficulty score illustrates that there were no significant changes in the past years where correlations between the difficulty score following rules that have been applied up to now were rather high.

If we compare the competitors' age at the WAG by years, we can conclude the increased complexity of COP in terms of DV and an increased number of deductions need longer competitive experience to be successful in the gymnastics community [21, 22]. This means that learning new, more complex and more demanding elements is a daily principle of the training process which increases the length of training [21]. Raising the age of a sports career in gymnastics also depends on other factors: general rules, physiological reasons, protecting children from harmful exposure, time training, early growth, growth of body segments, pubertal growth and maturation, sex characteristics, menarche, nutritional status, gymnastics training environment, familial factors, etc. [21]. For example, gymnast Simone Biles from (USA) is an amazing gymnast who continues to develop and challenge the norms of WAG with creative and technical ability and skill. At WCh 2019 in Stuttgart Biles successfully performed a new element on the Floor Exercise (FX), a triple double, which was given a J value. It is worth one point. Previously, the highest element value was I (9/10th of a point). Many athletes made their best results just in the years before the end of their sports careers. Nowadays, professional athletes are expected to leave sports after a certain age, but sometimes the reasons can be fooled. Namely, the average years of age have changed in the last 15 years [21]. The male gymnasts from 2003 to 2016 were on older by 2.3 years and female gymnasts by 3.3 years. "Sports like gymnastics should not be there for kids," said FIG ex-president Grandi. "Gymnasts should only be allowed to compete on the international stage when they are physically 
and mentally mature". Atiković (2020) in his results showed that the top female gymnasts' chronological age increased by 4.02 years [OG1996, $(n=105$, $\mathrm{M}=16.77, \mathrm{SD}=2.02) ; \mathrm{OG} 2000,(\mathrm{n}=97, \mathrm{M}=17.65, \mathrm{SD}=2.10) ; \mathrm{OG} 2004,(\mathrm{n}=98$, $\mathrm{M}=18.73, \mathrm{SD}=2.85) ; \mathrm{OG} 2008(\mathrm{n}=97, \mathrm{M}=19.01, \mathrm{SD}=3.03) ; \mathrm{OG} 2012$, $(\mathrm{n}=96$, $\mathrm{M}=20.43, \mathrm{SD}=3.65) ; \mathrm{OG} 2016,(\mathrm{n}=98, \mathrm{M}=20.79, \mathrm{SD}=4.36)$ [23]. In the forthcoming time, we do expect (with apparatus specialization) that age will rise.

Unlike other apparatus, the gymnastic all-around event VT has a completely different philosophy of grading. On the VT, gymnasts are allowed to perform only one element or one jump as opposed to other apparatus where the number of elements is significantly higher. On other apparatus, the gymnast should have in its composition 8 elements from different groups [4]. The VT itself was pre-announced to the judges' commission so that the commission and the audience already know in advance what the gymnast should perform in each of the vaulting phases. One harmless error during one of the vaulting phases on the VT can make the gymnast not take the announced jump at all and be approved by the judges. Unlike the VT on other apparatus of gymnastics all-around event, the competitor can also allow herself a mistake in one of the elements unlike the vault. Difficulty value and bonus points are already predetermined in the jump and presented at the level of rotation around the vertical and frontal axis. Unlike the vault on other apparatus, gymnasts have the opportunity to achieve bonus points for connections between certain elements. During training, time spent on VT is not the same as on the other apparatus in men's artistic gymnastics [24]. In the past, it was expected that the least amount of training time was spent on the VT, and the most amount of time was spent on the pommel horse (PH). Training times on other apparatus were similar (the gymnasts' preferences, abilities, and individual characteristics are also important in determining training time spent on each apparatus) [24].

Interesting research on the use of information communication technology for sporting purposes and their implementation in practice are presented in this article. Authors [25] have made the program execution jury "Judging RealTime System - RTJS" at the Australian Institute for Sport. The program has improved the objectivity of evaluation by jury E. Execution deductions are entered throughout the performance, and they cannot be modified; therefore, judges should deduct quickly and exactly anytime they see a mistake. Similar research under the title "judging in real time" mentioned the biggest problem of evaluation, namely reliability and validity. In his paper, the author mentions that the judges could use modern technology and with that, immediately after the performance, give their deductions so that a smaller number of judges would stay at rank [26].

According to the results of men's all-around qualifications at OG 2008, authors [27] purpose that the VT is considered to be the most valuable apparatus, and the $\mathrm{PH}$ was undervalued among all-around gymnasts. Using the COP, it is very hard to obtain a high $\mathrm{D}$ score on the $\mathrm{PH}$, whereas it is easier to obtain a high D score on the VT. Pairwise t-tests showed that D scores between the VT and other apparatus, and between the PH and other apparatus, were significantly different. Equality of disciplines has been tested by other authors [28]. The implications of the difficulty scores were tested on a sample of 49 all-around male gymnasts at the ECh 2009 in relation to their success in all-around competition. Only one group had a chance to win an all-around medal; difficulty scores between all six apparatus were not equal; the highest 
prediction of the all-around score was the parallel bars difficulty score. One of the attempts of identifying the most important routine apparatus for success in WAG at WCh was conducted in 2011 [29]. The factors least influenced by the technical standard of competitors were performance scores on UB and $\mathrm{BB}$ for women, and those on $\mathrm{PH}$ for men. For UB, BB, and PH scores were consistently good predictors of final standing. The results suggest that high scores on these apparatus have a greater influence on overall performance than scores on the other apparatus, regardless of the competitors' standard.

It is possible to conclude that field trials in artistic gymnastics are extremely complex in every way. Most of the papers focused on investigating the metric characteristics of judging. In the present study, they were investigating the reliability and validity of judging at ECh in Berlin 2011. In conclusion, the authors evaluated the quality of judging and found it comparable at the examined gymnastics competitions of different levels. The authors emphasized that further work must be done to analyze the inferior results at VT and FX apparatuses [16-19]. This interesting study [30] dealt with the predictors of success with spectators to serve as a judge and showed interesting results. The reliability of exercise presentation judging is the same as for official judges; ranking is analogous to the official judges and even higher. The analysis has allocated three groups of fans - strict, medium and permissive. With modern technology, e.g. smart mobile phones FIG could perform some experimental judging among fans.

Fujitsu Ltd has developed a judging system that can objectively score a routine based on the angles of a gymnast's joints. The system works by capturing the gymnasts' movements with a 3D laser sensor and analyzing them as numerical data. After 2020, the program is planned to calculate the difficulty value and execution score. This kind of technology will be able to make more objective judgments in artistic gymnastic. Additional sports presentation information will also be available for enhanced viewing by spectators within the arena, through television, or social media [31].

Technology has improved the accuracy, enjoyment, and experiences of both athletes and spectators at sporting events. Some of the key technological advancements that have been observed for athletes and spectators include improved time-tracking systems, clothing, and equipment, goal-line technology, video technology, GPS data tracking, virtual imaging, accuracy and decision systems (hawk-eye), coverage of events around the world via the internet and multiple devices. In athletics: tracking race times and clothing; football: goalline technology (GLT) and video technology (also known as VAR); rugby: data tracking (GPS tracking to collect data and stats on player performance) and video technology (hawk-eye video review technology is used by the television match official (TMO) to improve decision making); swimming: virtual imaging, divecam and swimsuits, tennis: hawk-eye line-calling system, radar guns and tennis racquets; gymnastics: instant replay and control system (IRCOS) and smart ring [25, 27, 32]. IRCOS as a program that will give judges an ability to immediately review routines visually. Judges can analyze a video in the case of a scoring dispute among the judges or a protest filed on behalf of a gymnast. $[25,27]$. In competitive men's artistic gymnastics an exercise on still rings is composed of swing, strength and hold positions. All strength and hold positions must be held for a minimum of 2 seconds; otherwise, a deduction for hold time of 0.3 points for each incomplete hold position will be applied in the execution score by the execution jury (E-jury). An innovative 
measurement system "smart rings" based on the forces that a gymnast has on both rings helps judges evaluate elements [32]. Both systems give vital edges for the review of gymnasts' exercises. It is certain that FIG would have to provide better evaluations in the future whether it is by using new modern technologies or a better value system of the composition.

In the past, authors [33-35] suggested multiplying exercise presentation by D score, but it was never implemented in the official FIG competitions. The ideal or preferred system for final score calculation is a matter of political decisions. From a historical point of view, many different ways of calculating the final score were used to evaluate gymnastics. Authors [36] compared 14 different models for calculating the final scores. Due to the simplicity of the VT (comparing to other disciplines, not stating vault is easy), those who VT well have the possibility of a higher final score of all-around. According to the analysis of the training loads, vault is also a discipline with the lowest amount of time spent [37].

J. Fujihara [38] proved a significant review of previous research. One of the objective ways to determine the start value of the vault is to use biomechanical characteristics of vault [5-7,39-41] try to define which biomechanical parameters explain and define the DV. With this type of research, authors $[6,7]$ have confirmed that the initial points on VT or other apparatus can be more objectively determined by the expert commission of the male and female technical committee of FIG. Unfortunately, the points of the WAG so far have been formed by experience rather than by scientific work and scientific research.

If we analyze the average points of all-around disciplines between 2017 and 2019, we can see that it is 11.687 pts, and that the VT differs from other apparatus by 1.559 pts. This is substantial information for coaches to know that with team performances they can make up for weaker performances on other apparatus and thus increase competitiveness especially in team competitions.

The marks in WAG especially on VT should be equal in the results of all disciplines, but it is not like that at the moment. The results of the conducted research may be a basis for the launch of the initial change of the COP 20202023 in relation to the existing system in WAG. The view of the change and the display of correlation prove that nothing significant has been changing in the past years where the difficulty value rate is remarkably high between the COP within the three cycles. This study has indicated that to achieve top performance in the all-around event, the crucial role is the results reached on the vault (VT).

\section{CONCLUSION}

In the analyzed results presented in this paper, the VT is scored significantly higher than other disciplines all-around the competitions. The biggest differences are even two points between the two apparatus vault (VT) and balance beam (BB). The system for discipline specialists works excellent. However, in all-around the problem still exists. The problem is within equality between disciplines as VT has special rules $[4,42,43]$ compared to UB, BB, and FX. Gymnast on VT shows in all-around one vault. Comparing to other disciplines vault is similar to one element from the exercise. In other Olympic sports, e.g. decathlon, they use special tables to give adequate points for each result. Coaches can use the results from this research to plan preparation tactics of gymnasts for all-around, team and apparatus competition. 


\section{ACKNOWLEDGMENTS}

The authors would like to acknowledge for all participation in the data collection.

\section{REFERENCES}

[1] Grossfeld A. Changes during the 110 years of the world artistic gymnastics championships. Sci Gymnastics J. 2014;6(2):5-27.

[2] Bučar PM. Primerjalna analiza tekmovalnih pravil v moški in ženski športni gimnastiki [Comparative analysis of Men's and Women's Code of points]. Diplomsko delo [Unpublished diploma thesis]. Faculty of Sport. Ljubljana. 1998.

[3] Fink H, Fetzer J. Proposals of the new Code of Points. International Symposium on Men's Artistic Gymnastics. FIG. Lugano. 1993.

[4] FIG. Code of Points for Women's Artistic Gymnastics Competitions 2017. Available at: http://www. fig-gymnastics.com/publicdir/rules/files/en_WAG\%20CoP\%202017-2020.pdf

[5] Atiković A. New Regression Models to Evaluate the Relationship between Biomechanics of Gymnastic Vault and Initial Vault Difficulty Values. J Hum Kinet. 2012;35:119-26. https://doi.org/10.2478/ v10078-012-0085-6

[6] Ferkolj MA. Kinematic analysis of the handspring double salto forward tucked on a new style of vaulting table. Sci Gymnastics J. 2010;2(1):35-48.

[7] Atiković A, Smajlović N. Relation between vault difficulty values and biomechanical parameters in men's artistic gymnastics. Sci Gymnastics J. 2011;3(3):91-105.

[8] Ansorge CJ, Scheer JK, Laub J, Howard J. Bias in judging women's gymnastics induced by expectations of within-team order. Res Q. 1978:49(4):399-405. https://doi.org/10.1080/10671315.1978.10615552

[9] Ansorge CJ, Scheer JK. International bias detected in judging gymnastic competition at the 1984 Olympic games. Res Q Exerc Sport. 1988:59(2):103-7. https://doi.org/10.1080/02701367.1988.106 05486

[10] Popović R. International bias detected in judging rhythmic gymnastics competition at Sydney-2000 Olympic Games. Facta universitatis-series: Phys Educ Sport. 2000:1:1-13.

[11] Ste-Marie DM. Expertise in women's gymnastic judging: An observational approach. Percept Motor Skills. 2000:90(2):543-6. https://doi.org/10.2466/pms.2000.90.2.543

[12] Ste-Marie DM, Valiquette SM, Taylor G. Memory-influenced biases in gymnastic judging occur across different prior processing conditions. Res Q Exerc Sport 2001;72(4):420-6. https://doi.org/10.1080 /02701367.2001.10608979

[13] Plessner H, Schallies E. Judging the cross on rings: A matter of achieving shape constancy. Appl Cognitive Psych. 2005:19(9):1145-56. https://doi.org/10.1002/acp.1136

[14] Boen F, van Hoye K, Vanden Auweele Y, Feys J, Smits T. Open feedback in gymnastic judging causes conformity bias based on informational influencing. J. Sports Sci. 2008;26(6):621-8. https://doi. org/10.1080/02640410701670393

[15] Dallas G, Kirialanis P. Judges' evaluation of routines in men's artistic gymnastics. Sci Gymnastics J. 2010;2(2):49-58.

[16] Leskošek B, Čuk I, Karácsony I, Pajek J, Bučar M. Reliability and validity of judging in men's artistic gymnastics at the 2009 University Games. Sci Gymnastics J. 2010;2(1):25-34.

[17] Bučar PM, Forbes W, Pajek J, Leskošek B, Čuk I. Reliability of real time judging system. Sci Gymnastics J. 2011;3(2):47-54

[18] Bučar M, Čuk I, Pajek J, Karácsony I, Leskošek B. Reliability and validity of judging in women's artistic gymnastics at University Games 2009. Eur J Sport Sci. 2012;12(3):207-15. https://doi.org/1 $0.1080 / 17461391.2010 .551416$

[19] Pajek MB, Čuk I, Pajek J, Kovač M, Leskošek B. Is the quality of judging in women artistic gymnastics equivalent at major competitions of different levels? J Hum Kinet. 2013;37(5):173-81. https://doi. org/10.2478/hukin-2013-0038

[20] Heiniger S, Mercier H. National Bias of International Gymnastics Judges during the 2013-2016 Olympic Cycle, 2018. Available at: https://arxiv.org/abs/1807.10033

[21] Atiković A, Delaš KS, Čuk I. Age trends in artistic gymnastic across World Championships and the Olympic Games from 2003 to 2016. Sci Gymnastics J. 2017;9(3):251-63.

[22] Atiković A, Delaš KS, Čuk I. Change the gymnastics minimum age requirements and the changes that have occurred in major competitions in women's artistic gymnastics. Acta Kinesiol. 2017;11(1):80-8.

[23] Atiković A. Anthropometric Characteristics of Olympic Female and Male Artistic Gymnasts from 1996 to 2016. Int J Morphol. (Revista Internacional de Morfología). 2020 Aug;38(4). https://doi. org/10.4067/S0717-95022020000400990

[24] Hadjijev N. Some problems of training young male gymnasts: FIG Symposium during Artistic Gymnastics World Championship. Stuttgart. 1989.

[25] Bučar PM, Forbes W, Pajek J, Leskošek B, Čuk, I. Reliability of Real Time Judging System (RTJS). Sci Gymnastics J. 2011;3(2):47-54.

[26] Sands B. Judging in "real time", 2011. Available at: http://gymnasticscoaching.com/ new/2010/11/ bills-sands-judging-in-real-time/ 
[27] Čuk I, Atiković A. Are Disciplines in All-around Men's Artistic Gymnastics Equal?. Sport Scientific \& Practical Aspects. 2009;6(1\&2):8-13.

[28] Čuk I, Forbes W. How apparatus difficulty scores affect all-around results in men's artistic gymnastics. Sci Gymnastics J. 2010;2(3):57-63.

[29] Massidda M, Calò CM. Performance scores and standings during the 43rd Artistic Gymnastics World Championships, 2011. J Sports Sci. 2012;30(13):1415-20. Fujiwara H, Ito K. ICT-based Judging Support System for Artistic gymnastics and Intended New World Created Through 3D Sensing Technology. Fujitsu Scientific \& Technical Journal. 2018;54(4):66-72.

[30] Aarts M, Pluk A. 1st report on "Smart Rings" presented during the 2nd European Union of Gymnastics (UEG) MAG Judges' Colloquium 5-7 December 2014, Frankfurt, Germany. UEG / InnoSportLab 's-Hertogenbosch, Internal report, 2014.

[31] Fink H. Towards an 'Alternative' Code of Points for Men and Women. FIG Judges' Symposium: The Future of Gymnastics, Rome. 1986.

[32] Fink H. A Code of Points for the Twenty-first Century. FIG International Judges' Symposium, Paris. 1991.

[33] Fink H, Fetzer J. Draft Proposal on Future Code of Points. FIGMTC, Barcelona. 1991.

[34] Čuk I, Fink H, Leskošek B. Modeling the final score in artistic gymnastics by different weights of difficulty and execution. Sci Gymnastics J. 2012;4(1)73-82.

[35] Čuk I, Karacsony I. Vault : Methods, Ideas, Curiosities, History. Ljubljana: ŠTD Sangvinčki. 2004.

[36] Fujihara J. Revisiting run-up velocity in gymnastics vaulting. 34 Conference of the International Society of Biomechanics in Sports, Tsukuba, Japan, 2016, 18-22, pp. 593-6.

[37] Fujihara T, Yamamoto E, Fuchimoto T. Run-up velocity in the gymnastics vault and its measurement. Japan J Phys Educ Hlth Sport Sci. 2017;62:435-53. https://doi.org/10.5507/ag.2012.012

[38] Farana R, Vaverka F. The effect of biomechanical variables on the assessment of vaulting in toplevel artistic female gymnasts in world cup competitions. Acta Gymnica. 2012;42(2):49-57. https:// doi.org/10.5507/ag.2012.012

[39] Farana R, Uchytil J, Zahradník D, Jandačka D. The “Akopian” vault performed by elite male gymnasts: Which biomechanical variables are related to a judge's score?. Acta Gymnica. 2015:45(1):33-40. https://doi.org/10.5507/ag.2015.005

[40] FIG. Code of Points for Women Artistic Gymnastics Competitions 2013. Available at: https://www. gymogturn.no/wp-content/uploads/2015/10/01-1-WAG-CoP-2013-2016-English-Feb-2013.pdf

[41] FIG. Code of Points for Women Artistic Gymnastics Competitions 2009. Available at: https://issuu. com/2008agwc/docs/01-1_wag_cop_2009-2012_english_ 